\title{
Synovial Sarcoma of the Thyroid Gland, Diagnostic Pitfalls and Clinical Management
}

\author{
CARINA OWEN $^{1}$, ANASTASIA CONSTANTINIDOU ${ }^{1,2,3}$, AISHA B. MIAH ${ }^{1,2}$, \\ KHIN THWAY ${ }^{1,2}$, CYRIL FISHER ${ }^{1}$, CHARLOTTE BENSON $^{1}$, SHANE ZAIDI ${ }^{1}$, \\ CHRISTINA MESSIOU ${ }^{1,2}$, WINETTE T.A. VAN DER GRAAF ${ }^{1,2}$ and ROBIN L. JONES ${ }^{1,2}$ \\ ${ }^{I}$ The Royal Marsden NHS Foundation Trust, London, U.K.; \\ ${ }^{2}$ The Institute of Cancer Research, London, U.K.; \\ ${ }^{3}$ Medical School University of Cyprus and BoC Oncology Centre, Nicosia, Cyprus
}

\begin{abstract}
Background/Aim: Synovial sarcoma is a soft tissue sarcoma that tends to affect young adults. There are few reports on primary synovial sarcoma of the thyroid and the aim of this study was to document the clinical and pathological features of synovial sarcoma occurring at this site. Case Presentation: A retrospective review of a prospectively maintained database was performed to identify patients with synovial sarcoma of the thyroid treated at the Royal Marsden Hospital between 2000 and 2017. Five patients were identified that underwent initial surgical management of localized disease. The mean age at presentation was 38 years, and male to female ratio was 4:1. In 3 out of 5 cases, the diagnosis of synovial sarcoma was made on the post-operative excision specimen. Two of these patients were treated at our institution on the development of metastatic disease. We conducted a literature review and identified 12 previously reported cases of synovial sarcoma of the thyroid. Conclusion: Synovial sarcoma of the thyroid is rare and can be challenging to diagnose. The clinical presentation is typically indistinguishable from that of thyroid cancer and most cases are diagnosed post-operatively on an excision specimen. The clinical and pathological features are similar to synovial sarcoma arising at other sites. In our experience, the rarity of the diagnosis can lead to difficulty in establishing the correct diagnosis and determining the appropriate treatment pathway. It is important that physicians are aware of this diagnosis to facilitate prompt referral to a specialist centre, for specialist follow-up and treatment which is different to the thyroid cancer pathway.
\end{abstract}

Correspondence to: Robin L. Jones, Sarcoma Unit, Royal Marsden Hospital, 203 Fulham Road, London, SW3 6JJ, U.K. Tel: +44 2078082137, Fax: +44 2078082113, e-mail: Robin.jones4@ nhs.net

Key Words: Synovial sarcoma, thyroid, diagnosis, pathology, therapy.
Soft tissue sarcomas are solid tumours of mesenchymal origin, comprising over 50 different histological subtypes. Synovial sarcoma comprises about $5 \%$ of all soft tissue sarcomas, and is a malignant mesenchymal neoplasm showing partial epithelial differentiation, which is characterized by a specific $\mathrm{t}(\mathrm{X} ; 18)(\mathrm{p} 11.2 ; \mathrm{q} 11.2)$ translocation leading to generation of SYT-SSX fusion gene transcripts (1). The median age of diagnosis of synovial sarcoma is in the late thirties, and over $65 \%$ of these tumours occur in the extremities, particularly the lower limbs (2). However, it has been shown to arise at almost any anatomic location, including viscera, and approximately $10 \%$ affect the head and neck region $(1,2)$. The thyroid is an exceptionally rare site, and to our knowledge there have only been 12 reported cases of synovial sarcoma of the thyroid gland in the literature (3-13).

The diagnosis of synovial sarcoma of the thyroid gland is challenging and may be delayed as the established diagnostic pathway for evaluation of focal thyroid nodules includes ultrasound with fine needle aspiration of equivocal lesions. Although this is usually sufficient for diagnosis of the more common thyroid pathologies, a diagnosis of sarcoma is challenging using cytology alone. Ideally if a diagnosis of sarcoma is suspected, core needle biopsy should be carefully planned and performed by a specialist to enable the biopsy tract to be excised subsequently during definitive surgery (14). However, as a rare diagnosis without specific imaging features, synovial sarcoma of the thyroid is rarely suspected. Polymerase chain reaction (PCR) or fluorescent in situ hybridization (FISH) can identify the characteristic chromosomal translocation (X;18), which is the most definitive molecular diagnostic test for synovial sarcoma. This translocation is present in over $90 \%$ of synovial sarcomas (1). Staging should include magnetic resonance imaging (MRI) of the neck for local staging and contrast enhanced computed tomography (CT) of the thorax, abdomen and pelvis to determine the 
presence of distant metastases (14). The commonest site for metastatic disease is the lung (15). Equivocal lesions can be further characterized by targeted US +/- sampling or FDG PET/CT.

The management of localized synovial sarcoma consists of surgery with or without radiation. The role of chemotherapy in the management of localized synovial sarcoma of any location remains controversial as it is indicated by a number of conflicting retrospective studies (16-18). In the metastatic setting, synovial sarcoma is considered a relatively chemosensitive subtype, with responses being observed particularly to ifosfamide based schedules (19-22). The aim of this study was to report our single-centre experience of the diagnostic trajectory and the clinical management of synovial sarcoma affecting the thyroid gland.

\section{Materials and Methods}

Institutional approval was obtained prior to commencing the study. We performed a retrospective search of a prospectively maintained database to identify patients with synovial sarcoma of the thyroid gland treated at the Royal Marsden between 2000 and 2017. Demographic, treatment and follow-up data were obtained from the electronic patient record. Chemotherapy for metastatic disease was administered using standard protocols with re-imaging performed after two cycles of therapy. Response was assessed using Response Evaluation Criteria in Solid Tumours (RECIST) 1.1. Descriptive statistics were employed.

The pathological diagnosis of synovial sarcoma was confirmed in all cases by two experienced soft tissue sarcoma pathologists (KT, CF). Molecular, genetic and cytogenetic analyses were performed on formalin-fixed, paraffin embedded (FFPE) material, for SS18 gene rearrangements by FISH or for SS18-SSX1 or SS18$S S X 2$ fusion transcripts by reverse transcription-polymerase chain reaction (RT-PCR). For FISH, 2-4 $\mu \mathrm{m}$ thick FFPE sections were dewaxed overnight at $60^{\circ} \mathrm{C}$, treated with wash buffer at $80^{\circ} \mathrm{C}(2-3$ h), incubated with proteolytic enzymes at $37^{\circ} \mathrm{C}$, and washed in distilled water followed by an alcohol wash series before addition of SS18 DNA probes (Vysis, Abbott Laboratories Ltd, Maidenhead, UK). Hybridization was performed overnight according to manufacturer's protocols. RT-PCR was performed according to standard, previously described methods (23).

\section{Results}

Five patients with synovial sarcoma of the thyroid gland were identified. Two of these patients were treated at the Royal Marsden Hospital. Both these male patients were treated with thyroidectomy at other hospitals under the local head and neck units, and one received post-operative radiation.

Case 1. The first patient, aged 37 years, presented with thyroid synovial sarcoma and was treated with thyroidectomy and post-operative radiotherapy at another hospital. He had no past medical history of note. Excision margins were clear and there was no distant metastatic disease at initial presentation. Whilst on follow-up, eight years later, he developed chest pain and haemoptysis, due to extensive chest wall, mediastinal and pulmonary metastatic disease. De-bulking surgery was undertaken bronchoscopically. Histopathology confirmed metastatic synovial sarcoma, and showed a relatively circumscribed cellular neoplasm, which entrapped lung parenchyma and was composed of elongated slender spindle cells with minimal pleomorphism and mitotic activity. Thyroid synovial sarcoma showed nuclear expression of TLE1 with focal bcl-2 positivity, but was negative for cytokeratins MNF116, AE1/AE3, and epithelial membrane antigen (EMA), S100 protein, CD34, TTF-1, CD99, WT1, SMA, desmin, MUC4, CD31, CD117, DOG1, EBER, STAT6, HHV8 and calretinin. FISH showed SS18 gene rearrangement, confirming the diagnosis. He was subsequently referred to the Royal Marsden Hospital, and repeat CT imaging showed a mediastinal and a left lower lobe lung metastasis. In view of the macroscopic metastatic disease, he was treated with doxorubicin and ifosfamide with subsequent disease regression. He tolerated combination chemotherapy well. Consolidation radiation comprising $50.4 \mathrm{~Gy}$ in 28 fractions was administered to the dominant site of disease recurrence in the left thorax followed by radiofrequency ablation to the distal left lower lobe lung lesion. In December 2015, after a follow-up period of 14 months without treatment, there was evidence of multi-focal disease progression in the lungs. He was commenced on second-line chemotherapy consisting of an infusional ifosfamide schedule $\left(1 \mathrm{~g} / \mathrm{m}^{2}\right.$ ifosfamide per day for 14 days of a 28-day cycle). The disease responded to ifosfamide and he received eight cycles in total but demonstrated progressive disease soon after. He commenced trabectedin two months later and received 4 cycles, but repeat imaging demonstrated progressive disease. He finally died 30 months following the diagnosis of metastatic disease.

Case 2. The second patient was a 47-year-old male who initially presented in 2013, when he noticed a left-sided thyroid nodule. At presentation, he was clinically well and asymptomatic. Past medical history included hypertension and hypercholesterolaemia, psoriasis with arthropathy, and a spontaneous pneumothorax at the age of 18 years old. He was a lifelong non-smoker. A core biopsy was performed at the local hospital, but the diagnosis was not established. A CT-positron emission tomography (PET) scan showed no distant sites of metastatic disease. A total thyroidectomy and bilateral lymph node dissection was subsequently performed at another hospital. The histopathology of the surgical specimen noted inflammatory cells, with the possibility of microscopic residual tumour cells. Lymph nodes were clear of metastatic disease. Review of the core biopsy at the Royal 

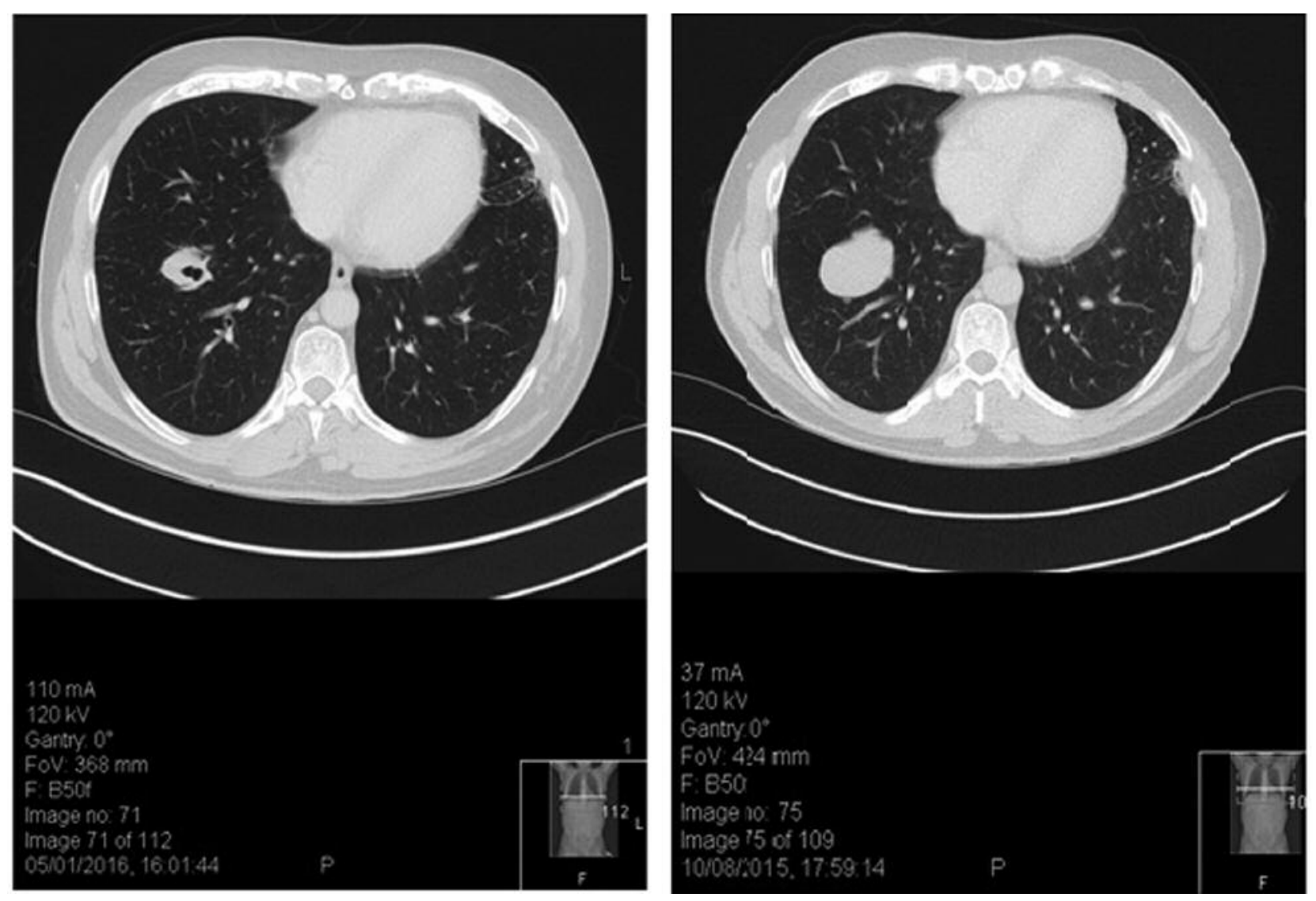

Figure 1. Response of lung metastases to chemotherapy. CT lung image of a 47-year old patient with previous history of synovial sarcoma who presented with multifocal pulmonary metastases. As shown in this image one of the metastatic lesions showed initial cavitation followed by dimensional shrinkage amounting to a partial response following six cycles of chemotherapy.

Marsden established that the tumour showed the biphasic pattern of synovial sarcoma, with fascicles of minimally atypical spindle cells with intermixed islands of epithelioid cells, sometimes forming a vague glandular pattern. Mitotic figures were prominent. Immunohistochemistry showed diffuse expression of CD56 and diffuse nuclear expression of TLE1, but no expression of cytokeratins or EMA. FISH showed SS18 gene rearrangement, and SS18-SSX2 fusion transcripts were detected by RT-PCR, confirming synovial sarcoma.

Following this pathology review, the patient was referred to our centre two years after initial diagnosis for surveillance. During this period, he was treated for persistent symptomatic hypocalcemia in the context of post-operative hypoparathyroidism, but was otherwise well and was not followed-up for his synovial sarcoma prior to being referred to the Royal Marsden. On assessment at our centre he was asymptomatic, however the chest radiograph showed multifocal pulmonary metastatic disease. As there was no suspicion on other primary tumors we concluded that he had metastases of his previous thyroidal synovial sarcoma. It was decided to start combination therapy with doxorubicin and ifosfamide to increase the chance of a volume response enabling subsequent local treatment of his metastases. He achieved a response to therapy and tolerated combination chemotherapy well. One of the metastatic lesions showed initial cavitation (Figure 1) followed by dimensional shrinkage amounting to a partial response following six cycles of chemotherapy. Cavitation can occur in metastatic soft tissue sarcoma including synovial sarcoma $(24,25)$. Following chemotherapy he underwent resection of the two right lung metastases followed by left thoracotomy and resection of a left upper lobe metastasis. Pathology from both surgical procedures confirmed the presence of metastatic synovial sarcoma. Due to pleural involvement of the left lung metastasis he was treated with post-operative radiation to the left upper lung. He subsequently developed recurrent disease in the left lung 11 months later. He was treated with 4 cycles of trabectedin and further surgery. Following this he was 
Table I. Literature review of previously reported cases of thyroid synovial sarcoma.

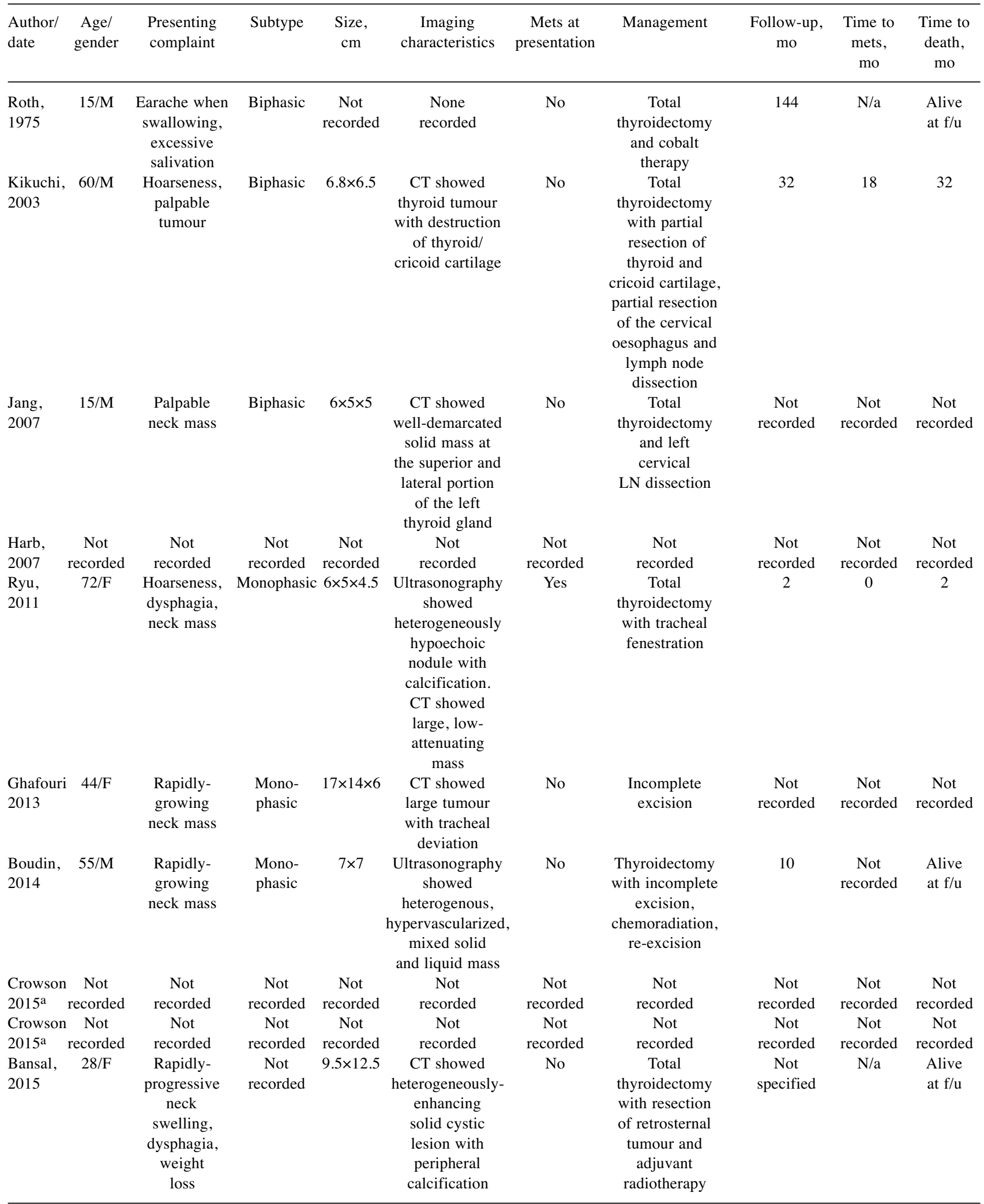


Table I. Continued

\begin{tabular}{|c|c|c|c|c|c|c|c|c|c|c|}
\hline $\begin{array}{l}\text { Author/ } \\
\text { date }\end{array}$ & $\begin{array}{l}\text { Age/ } \\
\text { gender }\end{array}$ & $\begin{array}{l}\text { Presenting } \\
\text { complaint }\end{array}$ & Subtype & $\begin{array}{l}\text { Size, } \\
\mathrm{cm}\end{array}$ & $\begin{array}{c}\text { Imaging } \\
\text { characteristics }\end{array}$ & $\begin{array}{c}\text { Mets at } \\
\text { presentation }\end{array}$ & Management & $\begin{array}{c}\text { Follow-up, } \\
\text { mo }\end{array}$ & $\begin{array}{l}\text { Time to } \\
\text { mets, } \\
\text { mo }\end{array}$ & $\begin{array}{c}\text { Time to } \\
\text { death, } \\
\text { mo }\end{array}$ \\
\hline $\begin{array}{l}\text { Murro, } \\
2015\end{array}$ & $41 / \mathrm{M}$ & $\begin{array}{l}\text { Dysphonia } \\
\text { and left } \\
\text { neck mass }\end{array}$ & Biphasic & $\begin{array}{l}\text { Not } \\
\text { recorded }\end{array}$ & $\begin{array}{l}\text { None } \\
\text { recorded }\end{array}$ & No & $\begin{array}{c}\text { Total } \\
\text { thyroidectomy } \\
\text { and subsequent } \\
\text { laryngopha- } \\
\text { ryngoeso- } \\
\text { phagectomyb }\end{array}$ & 13 & $\mathrm{~N} / \mathrm{a}$ & $\begin{array}{l}\text { Alive } \\
\text { at } \mathrm{f} / \mathrm{u}\end{array}$ \\
\hline $\begin{array}{l}\text { Shi, } \\
2016\end{array}$ & $31 / \mathrm{M}$ & $\begin{array}{c}\text { Large } \\
\text { asymptomatic } \\
\text { mass }\end{array}$ & Biphasic & $5 \times 2 \times 2$ & $\begin{array}{l}\text { Ultrasonography } \\
\text { showed } \\
\text { heterogenous, } \\
\text { hypervascular, } \\
\text { solid mass }\end{array}$ & No & $\begin{array}{c}\text { Total } \\
\text { thyroidectomy } \\
\text { with } \\
\text { incomplete } \\
\text { excision. } \\
\text { Chemotherapy } \\
\text { and LN } \\
\text { dissection } \\
\text { at relapse }\end{array}$ & 34 & 24 & $\begin{array}{l}\text { Alive } \\
\text { at } \mathrm{f} / \mathrm{u}\end{array}$ \\
\hline
\end{tabular}

${ }^{a}$ Crowson et al. reported 2 cases of thyroid synovial sarcoma within a study of synovial sarcomas of the head and neck; bAt initial operation, tumour was found to be arising from tracheoesophageal groove with direct extension into thyroid, trachea and oesophagus; Mo: months; F: female; M: male; CT: computed tomography; F/u: follow-up; Mets: metastases; LN: Lymph node.

treated with 6 months of pazopanib and his disease progressed rapidly. He deceased 31 months from diagnosis of metastatic disease.

Case 3. The third patient was a 42-year-old male, who had had a neck mass excised in 1997, which had been diagnosed elsewhere as paraganglioma. The patient developed locally recurrent disease and was referred to our institution for reexcision four years later. Grossly this comprised of thyroid tissue containing a $3.5 \mathrm{~cm}$ nodular lesion. Histology showed fibrous tissue and skeletal muscle containing cellular tumour composed of fascicles of minimally to mildly spindle cells with elongated or ovoid nuclei, indistinct nucleoli and scanty cytoplasm, and a mitotic index of up to $16 / 10 \mathrm{hpf}$. While no epithelial elements were discernible morphologically, reticulin staining showed a vaguely packeted arrangement of tumour cells. The tumour showed strong focal expression of EMA and bcl-2, with focal S100 protein, but was negative for MNF116, CAM5.2, CK903, CD99, CD34, CD117, SMA, HMB45, CD31, desmin and neurofilament. The tumour was present at the surgical margin. FISH showed SS18 gene rearrangement, confirming synovial sarcoma. The patient was found approximately one year later to have multiple lung metastases, two of which were excised, with histology confirming metastatic synovial sarcoma. The patient received conventional chemotherapy elsewhere with a good response but had no further followup at our institution.
Case 4. The fourth patient was a 36-year-old man who noticed a lump on his neck in July 2017, that was not fully investigated until August 2017, when he had a biopsy. Subsequent to this, he was lost to follow-up from the referring clinic. A biopsy that was taken was reviewed locally, but also seen at the RMH, and the diagnosis was confirmed as synovial sarcoma. These studies have shown evidence of a translocation involving the SS18 gene at $18 \mathrm{q} 11.2$. A staging CT scan on the 1st December 2017, showed a large mass in the right lobe of the thyroid gland $(5.7 \times 7.5 \mathrm{~cm}$ in the axal plane and craniocaudal, up to $9 \mathrm{~cm}$ ) as well as numerous lung nodules consistent with metastases. Due to his symptoms of shortness of breath and difficulty in swallowing, he was referred to the Royal Marsden. Due to the size and anatomic location of the tumour, it was deemed not resectable. He was commenced on combination doxorubicin and ifosfamide. His symptoms were improved and according to RECIST criteria the disease was radiologically stabilised. Subsequently he was treated with radiation and an ATR inhibitor within a clinical trial. He has recently completed radiation and is well.

Case 5. The fifth patient was a 30-year-old female with a tumour in the right thyroid lobe which involved adjacent structures in the neck. This patient was referred to our institution for pathology review alone. The excision specimen showed a cellular tumour, composed of sheets of relatively monotonous, mildly atypical rounded to ovoid 
cells with vesicular nuclei and scanty cytoplasm. The tumour was diffusely positive for CD56 and focally positive for cytokeratins and EMA, and a nested pattern was seen with reticulin stain. The features were consistent with poorly differentiated synovial sarcoma.

\section{Discussion and Conclusion}

Synovial sarcoma of the thyroid gland is an extremely rare condition, with only 12 published cases, four of which are reported within published series of synovial sarcomas of the head and neck (3-13). These include one report of thyroid involvement arising by direct extension of a primary synovial sarcoma in the tracheoesophageal groove, which was treated surgically (12). The published reported cases of synovial sarcoma arising in the thyroid are summarised in Table I. Our review of thyroid synovial sarcoma referred to the Royal Marsden since 2000 identified five patients, highlighting that this is an extremely rare diagnosis. The mean age of patients in our study was 38 (range $=30-47$ years), similar to the mean age of patients in previously reported cases, that was 40 . In all cases there was a higher frequency in males with a ratio of 4:1 in our study. The incidence of synovial sarcoma in any anatomic site is reported to be slightly higher in males than females. The rarity of the tumour in the thyroid gland makes it an unexpected clinical and pathological finding in practice, which can be challenging to diagnose. Synovial sarcoma is itself a rare subtype comprising about $5 \%$ of soft tissue sarcomas, with an incidence of 1-3 cases per million, and 81 new cases in the UK in 2010 (26). Both anaplastic and medullary thyroid carcinoma are rare. These are the two rarest subtypes of thyroid cancer, each comprising about 3\% of thyroid cancer cases. The incidence of thyroid cancer in the UK is 3.0 per 100,000 men and 7.4 per 100,000 women, with follicular thyroid cancer being the most common subtype (27). Typically, there are 70-90 new cases of anaplastic carcinoma each year in the UK (28). Synovial sarcoma of the thyroid gland typically presents with a neck mass, which may be rapidly progressive, and there may be associated symptoms such as hoarseness of voice or dysphagia. In our experience, the clinical presentation can be indistinguishable from that of thyroid cancer. Histologically, synovial sarcomas can be purely spindle cell neoplasms (monophasic variant), mixed spindle and epithelioid cell neoplasms (with glandular or other epithelial structures in varying degrees of differentiation) (biphasic type) or round cell tumours (poorly differentiated type), with focal cytokeratin and EMA expression and often CD56 expression (1). These can therefore easily be mistaken for poorly differentiated, sarcomatoid or neuroendocrine carcinomas. Pre-operative fine needle aspiration cytology (FNAC) was described in five of the previously reported cases of thyroid synovial sarcoma. In four of these $(3,5,11,12)$ the impression following FNAC was of medullary or dedifferentiated/anaplastic thyroid carcinoma, and in the fifth case the specimen was regarded as a benign follicular lesion (4). In all previously reported cases, the diagnosis of synovial sarcoma was made post-operatively, on an excision specimen. We report a similar experience here, where 3 out of 5 cases referred to our centre were diagnosed on post-operative excision specimens. One patient underwent core biopsy prior to surgery, which was identified as synovial sarcoma on review by a sarcoma pathology specialist at our centre.

The initial diagnostic investigation of choice in suspected thyroid cancer is ultrasound-guided fine needle aspiration cytology (FNAC). The diagnosis of thyroid malignancy cannot always be made on FNAC alone, and in such cases the patient may undergo diagnostic surgery (29). In all reported instances, the diagnosis of synovial sarcoma of the thyroid was not established by FNAC. The cytology is more likely to be interpreted as suggestive of medullary or anaplastic carcinoma, in keeping with observed cytological similarities. On imaging, necrosis which is often encountered in synovial sarcomas could be mistaken for cystic change in benign thyroid nodules (15), and calcifications are encountered in common thyroid pathologies and synovial sarcoma. Therefore, core needle biopsy should be considered following inconclusive ultrasound and cytology of a thyroid nodule particularly where irregular solid elements are identified. In cases where medullary thyroid carcinoma is suspected on FNAC, patients may proceed directly to total thyroidectomy and selective lymph node dissection (29). Conversely, lymph node involvement is less often encountered in synovial sarcoma, which has a tendency towards haematogenous spread (30). One should avoid selective lymph node dissection in these cases unless imaging raises suspicion.

It is important for clinicians who encounter thyroid problems to be aware of this tumour type and its ability to present rarely in the thyroid gland. Early identification is essential to facilitate appropriate referral to a dedicated sarcoma centre. Dedicated follow-up is required to monitor for local and distant recurrence, which is completely different from the thyroid cancer follow-up pathway. Surgical resection remains the mainstay of management for localized synovial sarcoma with or without radiation (2). Some retrospective studies have reported an improvement in local control and disease-free survival conferred by radiotherapy (31-33), which may be administered in the pre-operative or postoperative setting. In five of the previously reported thyroid cases, complete excision of the primary tumour was not possible at initial operation $(5,6,7,12,13)$. In such cases it is especially pertinent to establish the diagnosis in order to plan appropriate adjuvant treatment. Four out of five patients in our series developed metastatic disease suggesting that synovial sarcoma affecting the thyroid gland has an 
aggressive clinical course. In two of those the interval between primary diagnosis and metastatic disease was more than five years. Although the disease is typically aggressive in its course, late metastases may occur, as illustrated by its course in our patients. Both patients referred to our institution for further management and were treated with the combination of doxorubicin and ifosfamide. These patients responded to chemotherapy again consistent with a diagnosis of synovial sarcoma arising at other primary sites.

In summary, we described our institutional experience of synovial sarcoma arising in the exceptionally rare location of the thyroid gland. The rarity of the diagnosis can lead to difficulty in establishing the correct diagnosis and determining the appropriate treatment pathway, as has been observed in our experience. While the pathological features of primary synovial sarcoma of the thyroid gland are similar to synovial sarcoma arising at other primary sites, the rarity of the tumor at this location may lead to pathological misdiagnoses. Furthermore, there is an evident need of centralised and individualised treatment in a facility with both expertise in sarcoma and local treatment of head and neck tumours in order to optimise the chance of cure and prevent unnecessary late effects of treatment. Finally, it is important to realise that metastatic spread may occur years after the primary diagnosis.

\section{Conflicts of Interest}

No competing financial interests exist. Institutional approval was granted for this study and it adheres to ethics guidelines and legal requirements in the UK.

\section{References}

1 Thway K and Fisher C: Synovial sarcoma: defining features and diagnostic evolution. Ann Diagn Pathol 18(6): 369-380, 2014.

2 Vlenterie M, Ho VK, Kaal SE, Vlenterie R, Haas R and van der Graaf WT: Age as an independent prognostic factor for survival of localized synovial sarcoma patients. Br J Cancer 113(11): 1602-1606, 2015.

3 Kikuchi I, Anbo J, Nakamura S, Sugai T, Sasou S, Yamamoto M, Oda Y, Shiratsuchi H and Tsuneyoshi M: Synovial sarcoma of the thyroid. Report of a case with aspiration cytology findings and gene analysis. Acta Cytol 47(3): 495-500, 2003.

4 Jang KS, Min KW, Jang SH, Paik SS, Tae K, Jang SJ and Park $\mathrm{MH}$ : Primary synovial sarcoma of the thyroid gland. J Korean Med Sci 22 Suppl: S154-158, 2007.

5 Ryu CH, Cho KJ and Choi SH: Synovial sarcoma of the thyroid gland. Clin Exp Otorhinolaryngol 4(4): 204-206, 2011.

6 Ghafouri A, Anbara T, Mir A, Lashkari M and Nazari M: Thyroid synovial sarcoma: a case report. Acta Med Iran 51(1): 69-72, 2013

7 Boudin L, Fakhry N, Chetaille B, Perrot D, Nguyen A.T, Daidj N, Guiramand J, Sarran A, Moureau-Zabotto L and Bertucci F: Primary synovial sarcoma of the thyroid gland: case report and review of the literature. Case Rep Oncol 7(1): 6-13, 2014.
8 Roth JA, Enzinger FM and Tannenbaum M: Synovial sarcoma of the neck: a followup study of 24 cases. Cancer 35(4): 1243$1253,1975$.

9 Harb WJ, Luna MA, Patel SR, Ballo MT, Roberts DB and Sturgis EM: Survival in patients with synovial sarcoma of the head and neck: association with tumor location, size, and extension. Head Neck 29(8): 731-740, 2007.

10 Crowson MG, Lalich I, Keeney MG, Garcia JJ and Price DL: Clinicopathologic factors and adjuvant treatment effects on survival in adult head and neck synovial cell sarcoma. Head Neck 37(3): 375-380, 2015.

11 Bansal N, Ranade RS and Mishra A: Synovial sarcoma mimicking thyroid carcinoma. ANZ J Surg 87(11): E214-E215, 2017.

12 Murro D, Slade JM, Syed S and Gattuso P: Fine needle aspiration of secondary synovial sarcoma of the thyroid gland. Diagn Cytopathol 43(11): 928-932, 2015.

13 Shi RL, Qu N, Gao LL, Lu ZW, Sun GH and Ji QH: Primary synovial sarcoma of the thyroid with locally repeated relapses in short periods: A case report. Biomed Rep 5(1): 79-82, 2016.

14 Dangoor A, Seddon B, Gerrand C, Grimer R, Whelan J and Judson I: UK guidelines for the management of soft tissue sarcomas. Clin Sarcoma Res 6: 20, 2016.

15 Murphey MD, Gibson MS, Jennings BT, Crespo-Rodríguez AM, Fanburg-Smith $\mathbf{J}$ and Gajewski DA: Imaging of synovial sarcoma with radiologic-pathologic correlation. Radiographics 26(6): 1543-1565, 2006

16 Eilber FC, Brennan MF, Eilber FR, Eckardt JJ, Grobmyer SR, Riedel E, Forscher C, Maki RG and Singer S: Chemotherapy is associated with improved survival in adult patients with primary extremity synovial sarcoma. Ann Surg 246(1): 105113, 2007.

17 Lewis JJ, Antonescu CR, Leung DH, Blumberg D, Healey JH, Woodruff JM and Brennan MF: Synovial sarcoma: a multivariate analysis of prognostic factors in 112 patients with primary localized tumors of the extremity. J Clin Oncol 18(10): 20872094, 2000.

18 Al-Hussaini H, Hogg D, Blackstein ME, O'Sullivan B, Catton CN, Chung PW, Griffin AM, Hodgson D, Hopyan S, Kandel R, Ferguson PC, Wunder JS and Gupta AA: Clinical features, treatment, and outcome in 102 adult and pediatric patients with localized high-grade synovial sarcoma. Sarcoma 2011: 231789, 2011.

19 Nielsen OS, Judson I, van Hoesel Q, le Cesne A, Keizer HJ, Blay JY, van Oosterom A, Radford JA, Svancárová L, Krzemienlecki K, Hermans C, van Glabbeke M, Oosterhuis JW and Verweij J: Effect of high-dose ifosfamide in advanced soft tissue sarcomas. A multicentre phase II study of the EORTC Soft Tissue and Bone Sarcoma Group. Eur J Cancer 36(1): 61-67, 2000.

20 Ferrari A, Gronchi A, Casanova M, Meazza C, Gandola L, Collini P, Lozza L, Bertulli R, Olmi P and Casali PG: Synovial sarcoma: a retrospective analysis of 271 patients of all ages treated at a single institution. Cancer 101(3): 627634, 2004.

21 Rosen G, Forscher C, Lowenbraun S, Eilber F, Eckardt J, Holmes C and Fu YS: Synovial sarcoma. Uniform response of metastases to high dose ifosfamide. Cancer 73(10): 2506-2511, 1994. 
22 Vlenterie $\mathrm{M}$, Litière $\mathrm{S}$, Rizzo $\mathrm{E}$, Marréaud S, Judson I, Gelderblom H, Le Cesne A, Wardelmann E, Messiou C, Gronchi A and van der Graaf WT: Outcome of chemotherapy in advanced synovial sarcoma patients: Review of 15 clinical trials from the European Organisation for Research and Treatment of Cancer Soft Tissue and Bone Sarcoma Group; setting a new landmark for studies in this entity. Eur J Cancer 58: 62-72, 2016.

23 Thway K, Rockcliffe S, Gonzalez D, Swansbury J, Min T, Thompson L and Fisher C: Utility of sarcoma-specific fusion gene analysis in paraffin-embedded material for routine diagnosis at a specialist centre. J Clin Pathol 63: 508-512, 2010.

24 Cohen MC and Drut R: Persistent interstitial pulmonary emphysema-like cyst associated with metastatic synovial sarcoma. Pediatr Dev Pathol 3(4): 391-393, 2000.

25 Hoag JB, Sherman M, Fasihuddin Q and Lund ME: A comprehensive review of spontaneous pneumothorax complicating sarcoma. Chest 138(3): 510-518, 2010.

26 Cancer Research UK, Soft tissue sarcoma incidence statistics. http://www.cancerresearchuk.org/health-professional/cancerstatistics/statistics-by-cancer-type/soft-tissue-sarcoma/incidence. Accessed May 17, 2017.

27 Cancer Research UK, Thyroid cancer incidence statistics. http://www.cancerresearchuk.org/health-professional/cancerstatistics/statistics-by-cancer-type/thyroid-cancer/incidence. Accessed May 17, 2017.

28 OCIU: UK data estimated from England thyroid cancer data provided by Oxford Cancer Intelligence Unit, 2012.
29 Perros P, Boelaert K, Colley S, Evans C, Evans RM, Gerrard Ba G, Gilbert J, Harrison B, Johnson SJ, Giles TE, Moss L, Lewington V, Newbold K, Taylor J, Thakker RV, Watkinson J, Williams GR and British Thyroid Association: Guidelines for the management of thyroid cancer. Clin Endocrinol (Oxf) 81(Suppl 1): 1-122, 2014.

30 Daigeler A, Kuhnen C, Moritz R, Stricker I, Goertz O, Tilkorn D, Steinstraesser L, Steinau HU and Lehnhardt M: Lymph node metastases in soft tissue sarcomas: a single center analysis of 1,597 patients. Langenbecks Arch Surg 394(2): 321-329, 2009.

31 Guadagnolo BA, Zagars GK, Ballo MT, Patel SR, Lewis VO, Pisters PW, Benjamin RS and Pollock RE: Long-term outcomes for synovial sarcoma treated with conservation surgery and radiotherapy. Int J Radiat Oncol Biol Phys 69(4): 1173-1180, 2007.

32 Shi W, Indelicato DJ, Morris CG, Scarborough MT, Gibbs CP and Zlotecki RA: Long-term treatment outcomes for patients with synovial sarcoma: a 40-year experience at the University of Florida. AM J Clin Oncol 36(1): 83-88, 2013.

33 Naing KW, Monjazeb AM, Li CS, Lee LY, Yang A, Borys D and Canter RJ: Perioperative radiotherapy is associated with improved survival among patients with synovial sarcoma: A SEER analysis. J Surg Oncol 111(2): 158-164, 2005.

Received July 25, 2018

Revised August 12, 2018

Accepted August 21, 2018 